\title{
Determination of Mercury in Alcoholic Drinks by ICP-MS After Matrix-Assisted Photochemical Vapor Generation
}

\author{
Ying Gao ${ }^{\text {a* }}$, Xiuhong Peng ${ }^{a}$, Zeming Shi ${ }^{a}$, Ruoxi Zhang ${ }^{a}$, Xiaofeng Xia $^{a}$, Furong Yue ${ }^{a}$, and Rui Liu \\ ${ }^{a}$ College of Nuclear Technology and Automation Engineering, Chengdu University of Technology, \\ Chengdu, Sichuan 610059, P.R. China \\ b College of Chemistry, Sichuan University, Chengdu, Sichuan 610064, P.R. China
}

\begin{abstract}
In this work, we demonstrate a highly sensitive matrix-assisted photochemical vapor generation (MA photo CVG) method for the determination of mercury in alcoholic drinks using a PerkinElmer ELAN ${ }^{\circledR}$ DRC TM -e ICP-MS. Without adding any additional reducing reagent, volatile mercury vapor was liberated from the ethanol-containing matrix under irradiation of an ultraviolet source. The generated mercury vapor was transported to the ICPMS with argon as a carrier gas. No interferences were observed from $\mathrm{Fe}, \mathrm{Co}, \mathrm{Cu}, \mathrm{Zn}$, and $\mathrm{Ni}$ at 5000 times the concentration of $\mathrm{Hg}$ in solution. Due to the high sample introduction efficiency over the typical $2-5 \%$ associated with pneumatic solution nebulization, the limit of detection (LOD) was enhanced more than several ten-fold compared to the results obtained using pneumatic nebulization.
\end{abstract}

Under the optimized conditions, a limit of detection $(3 \sigma)$ of $3 \mathrm{pg} \mathrm{mL} \mathrm{m}^{-1} \mathrm{Hg}$ was obtained with the dynamic linear range over 0.05 to $2 \mathrm{ng} \mathrm{mL}^{-1}$. The repeatability, expressed as the relative standard deviation $(n=7)$, was $2.3 \%$ (one day) and $3.1 \%$ (day-to-day) for mercury determination at the concentration of $0.5 \mathrm{ng} \mathrm{mL}^{-1}$. To validate the accuracy of the method, several samples, including water certified reference materials and alcoholic drinks, were tested by the proposed method. The results were in good agreement with the certified values or those obtained by traditional chemical vapor generation atomic fluorescence spectrometry (CVG-AFS). To the best of our knowledge, this is the first report of combining matrix-assisted photo CVG with ICP-MS analysis. The method is characterized as highly sensitive, simple, green, and cost-effective.

\section{INTRODUCTION}

Chemical vapor generation (CVG) is widely regarded as a sample introduction technique for atomic spectrometry, with the advantages of efficient matrix separation, high analyte transport efficiency, and high selectivity and sensitivity (1-5). Recently, photo CVG was demonstrated to be a powerful alternative to conventional CVG owing to its simplicity, versatility, and cost-effectiveness $(6,7)$. In photo CVG, volatile chemical vapors are generated from non-

*Corressponding author

E-mail: ying.gaoy@gmail.com volatile precursors by the irradiation of ultraviolet (UV) sources in the presence of low molecular weight organic compounds such as alcohols, aldehydes, or carboxylic acids (8). This technique retains the principal advantages of conventional CVG, but further provides for simpler reactions, expanded elemental coverage, greener analytical chemistry, and cost-effectiveness. Methods for the determination of Hg (9,10), Cd (11), conventional hydride-forming elements (As, Bi, $\mathrm{Sb}, \mathrm{Se}, \mathrm{Te})$ (12-14), transition metals $(\mathrm{Ni}, \mathrm{Co}, \mathrm{Fe})(15,16)$, and nonmetals (I) (17) have proven to be successful. It is worth mentioning that Hou et al. (18) reported the combination of matrix-assisted photo CVG (MA photo CVG) with atomic fluorescence spectrometry (AFS) for the determination of mercury in wine and liquor samples. Thanks to the intrinsic low molecular weight organic compounds (ethanol), the method required no additional reagents for photo CVG and showed high detection sensitivity.

Inductively coupled plasma mass spectrometry (ICP-MS) is unarguably the predominant and most sensitive commercial instrumental technique for the determination of a wide range of metals and several nonmetals (19-23). The advantages of ICP-MS include low detection limits, low matrix effects, wide dynamic range, and high spectral resolution. Correspondingly, besides conventional pneumatic solution nebulization, ICP-MS has been coupled with photochemical vapor generation (9). This approach is efficiently applied to further enhance the sensitivity and detection power by increasing the sample introduction efficiency beyond the typical 2-5\% associated with pneumatic solution nebulization, and to avoid or alleviate matrix interferences $(15,24)$. The detection sensitivities can be enhanced over several ten- to several hundred-fold for different elements, compared to those obtained using pneumatic nebulization sample introduction (15).

Despite the increased interest in photo CVG over the past few years, applications to real sample matrices remain limited. The purpose of this work is to explore the potential advantages of sample matrixassisted photo CVG as a sample 
introduction technique when coupled with the high accuracy and sensitivity offered by ICP-MS. To the best of our knowledge, this is the first report of combining matrix-assisted photo CVG and ICPMS. The experimental conditions, including the optimization of photo-chemical vapor generation parameters, potential interferences from transition metals, analytical performance, and method validation by analysis of real alcoholic drink samples, were investigated and are discussed in detail.

\section{EXPERIMENTAL}

\section{Instrumentation}

A schematic of the photo CVG system, hyphenated to a model ELAN $^{\circledR}{ }^{\circledR}$ DRC ${ }^{\text {TM }}$-e ICP-MS (PerkinElmer, Inc., Shelton, CT, USA), is shown in Figure 1. A model FIA-3110 flow injection system (Vital Instruments Co. Ltd., Beijing, P.R. China) was used for solution sample introduction to the photo CVG system. A low-pressure $\mathrm{Hg}$ vapor UV lamp (15 W, Philips Co., Holland), fitted with a quartz tube $(20 \mathrm{~cm} \times 1.8 \mathrm{~mm}$ i.d. $\times 2.8 \mathrm{~mm}$ o.d.), was employed as the photo CVG system. The photo CVG system was wrapped with aluminum foil, which served to protect the operator's skin and eyes from UV radiation. In order to obtain a stable plasma, the photo
CVG system was connected to a set of two gas liquid separators (GLSs) (Chengdu Guoxiang Instrument Co., Ltd., P.R. China) which are directly connected to the ICP torch. The use of two GLSs efficiently eliminates the water vapor and coexisting volatile organic compounds in the sample solution. Optimization of the ELAN DRC-e was performed as recommended by the manufacturer; optimization of the detection conditions for photochemical vapor generation was undertaken independently. The operating conditions are summarized in Table I.

\section{Reagents and Samples}

All chemicals were of at least analytical reagent grade. Working standard solutions of mercury were prepared prior to use by appropriate step dilutions of a mercury stock standard solution of $1000 \mathrm{mg} \mathrm{L}^{-1}$ purchased from the National Research Center for Standard Materials (NRCSM) of P.R. China. NRCSM certified reference materials, GBW(E) 080329 Water and GBW(E) 080939 Water, were used to validate the accuracy of the method. Working solutions of ethanol were diluted from analytical reagent grade ethanol with deionized water (DIW). The alcoholic drinks used in this work were purchased at local markets and

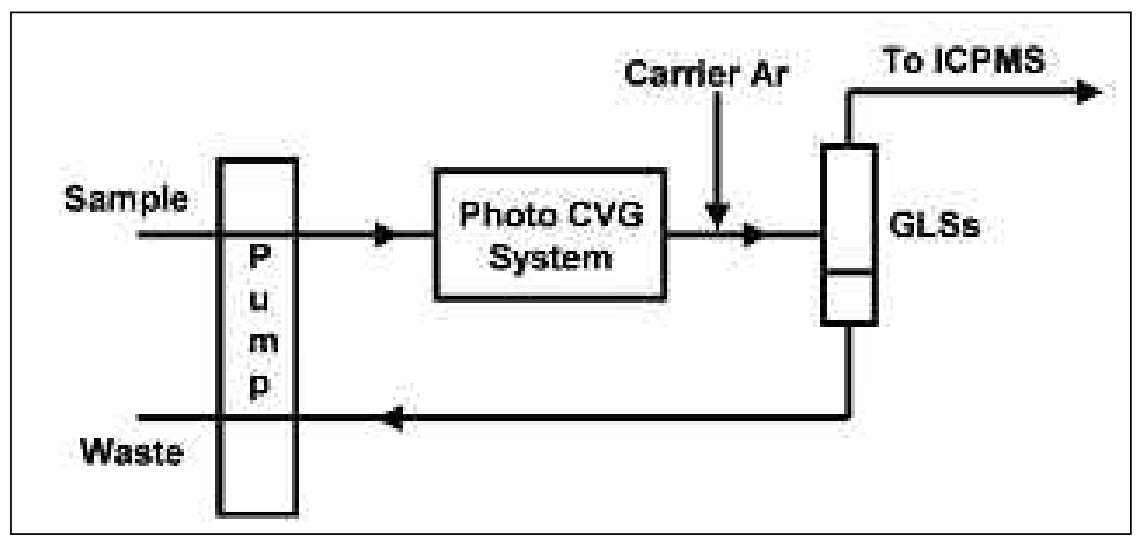

Fig. 1. Schematic of the matrix-assisted photo CVG-ICP-MS instrumentation. GLSs: gas-liquid separators.

used without pretreatment. Spiked alcoholic drinks were prepared fresh by adding a certain amount of inorganic mercury $\left(\mathrm{Hg}^{2+}\right)$ standard solution.

\section{Analytical Procedure}

The mercury- and ethanol-containing solution was brought into the photo CVG system by the flow injection pump. The photo $\mathrm{CVG}$ system was irradiated by UV light during the continuous introduction of the sample. The produced mercury vapor was carried out by an argon flow after photo CVG. Subsequently, a tandem set of two GLSs was employed for the separation of mercury vapor from water and coexisting volatile organic compounds, and mercury vapor was introduced into the ICP torch for detection of the ${ }^{202} \mathrm{Hg}$ signal.

\section{RESULTS AND DISCUSSION}

\section{Optimization of Detection Conditions for Photo CVG}

The argon carrier gas flow rate, the sample flow rate through the photo CVG system, and the ethanol concentration comprised the three basic parameters which determined the mercury vapor generation and transport efficiency to the ICP-MS.

TABLE I

ICP-MS Instrumental Operating Parameters

\begin{tabular}{|c|c|}
\hline Parameters & Values \\
\hline RF power & $1300 \mathrm{~W}$ \\
\hline Cool gas flow & $13 \mathrm{~L} \mathrm{~min}^{-1}$ \\
\hline Auxiliary gas flow & $0.8 \mathrm{~L} \mathrm{~min}^{-1}$ \\
\hline Nebulizer gas flow & $0.7 \mathrm{~L} \mathrm{~min}^{-1}$ \\
\hline Scanning mode & eak hopping \\
\hline Resolution & $\operatorname{ard}(0.7 \mathrm{amu})$ \\
\hline Dwell time & $30 \mathrm{~ms}$ \\
\hline Sweeps per reading & 5 \\
\hline Readings per replicate & 1 \\
\hline Number of replicates & 4 \\
\hline Sample flow rate & $8.0 \mathrm{~mL} \mathrm{~min}^{-1}$ \\
\hline Isotope monitored & ${ }^{202} \mathrm{Hg}$ \\
\hline
\end{tabular}




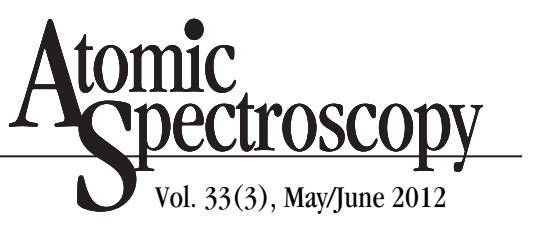

\section{The Effect of Argon Carrier Gas Flow Rate}

The argon carrier gas served as the sampling gas to bring the generated mercury vapor to the GLSs and the ICP torch from the photo CVG system. As shown in Figure 1, the carrier gas was introduced after the photo $C V G$ reactor rather than before the cell. Obviously, the analyte transport would be more efficient if the carrier gas were introduced into the cell. However, introduction of the carrier gas into the cell would largely decrease the UV irradiation time on the samples. Thus, this instrument configuration was used.

The effect of Ar carrier gas flow rate for the determination of $0.5 \mathrm{ng} \mathrm{mL}^{-1} \mathrm{Hg}$ is presented in Figure $2 \mathrm{a}$. The optimum sensitivities were obtained at flow rates of $0.7 \mathrm{~L} \mathrm{~min}^{-1}$. The sensitivities decreased at both lower and higher values as a consequence of the related effects of optimal depth of sampling in the plasma, analyte gas/liquid partitioning efficiency, and dilution. Thus, a $0.70 \mathrm{~L} \mathrm{~min}^{-1}$ argon carrier gas flow rate was chosen for all subsequent measurements.

\section{The Effect of Ethanol Concen- tration}

It was found in earlier research that the efficiency of mercury vapor generation depended strongly on the reductant concentration $(8,25)$. As shown in Figure $2 \mathrm{~b}$, the intensity of ${ }^{202} \mathrm{Hg}$ increased with a concentration of ethanol for 5 to $10 \%(\mathrm{v} / \mathrm{v})$. The amount of radicals increased with the concentration of ethanol; hence, the rate of reaction accelerated and resulted in an increase in signal intensity. A plateau appeared when the ethanol concentration was higher than $10 \%$. During this plateau, the amount of reductant-generated radicals is enough for the reduction of $\mathrm{Hg}^{2+}$ to $\mathrm{Hg}^{0}$ under the irradiation of
UV. In consideration of both sensitivity and reagent savings, 10\% ethanol was used for this study.

\section{The Effect of Sample Introduc- tion Flow Rate}

The effect of sample introduction flow rate ranging from 3-8 $\mathrm{mL}$ $\mathrm{min}^{-1}$ was investigated for the determination of $\mathrm{Hg}$ at $0.5 \mathrm{ng} \mathrm{mL}^{-1}$ (see Figure 2c). This parameter primarily determines the residence time of the solution in the photo $\mathrm{CVG}$ reactor and the efficiency of the radicalinduced generation reaction. The sensitivity increases almost linearly with an increase in sample introduction flow rate over the tested range. The higher the sample introduction flow rate, the higher the sample introduction will be obtained in a given sampling time, which will consequently increase the detection sensitivity. These observations also validate the fast kinetics of mercury photo reduction by ethanol (18), and shows that the decrease of UV irradiation time caused by the high sample introduction flow rate has no significant effect. A flow rate of $8.0 \mathrm{~mL} \mathrm{~min} \mathrm{mas}^{-1}$ welected for all subse-quent measurements.

\section{Matrix Effects}

In traditional chemical vapor generation methods, the transition metals, such as $\mathrm{Cu}, \mathrm{Co}$, and $\mathrm{Ni}$, can seriously affect the determination of mercury. In the current investigation, no interferences were observed from $5 \mathrm{mg} \mathrm{L}^{-1} \mathrm{Fe}$, Co, $\mathrm{Cu}, \mathrm{Zn}$, and $\mathrm{Ni}$ to $1 \mu \mathrm{g} \mathrm{L}^{-1} \mathrm{Hg}^{2+}$ (5000-fold), with satisfactory recoveries higher than $95 \%$. In addition to studying the interferences from transition metals, the organic sample matrix for the determination of mercury was also investigated. The analytical response between different alcoholic drinks varied by $20 \%$, which correlated with the variation in ethanol content of the drinks tested. Therefore, the standard addition method was used for

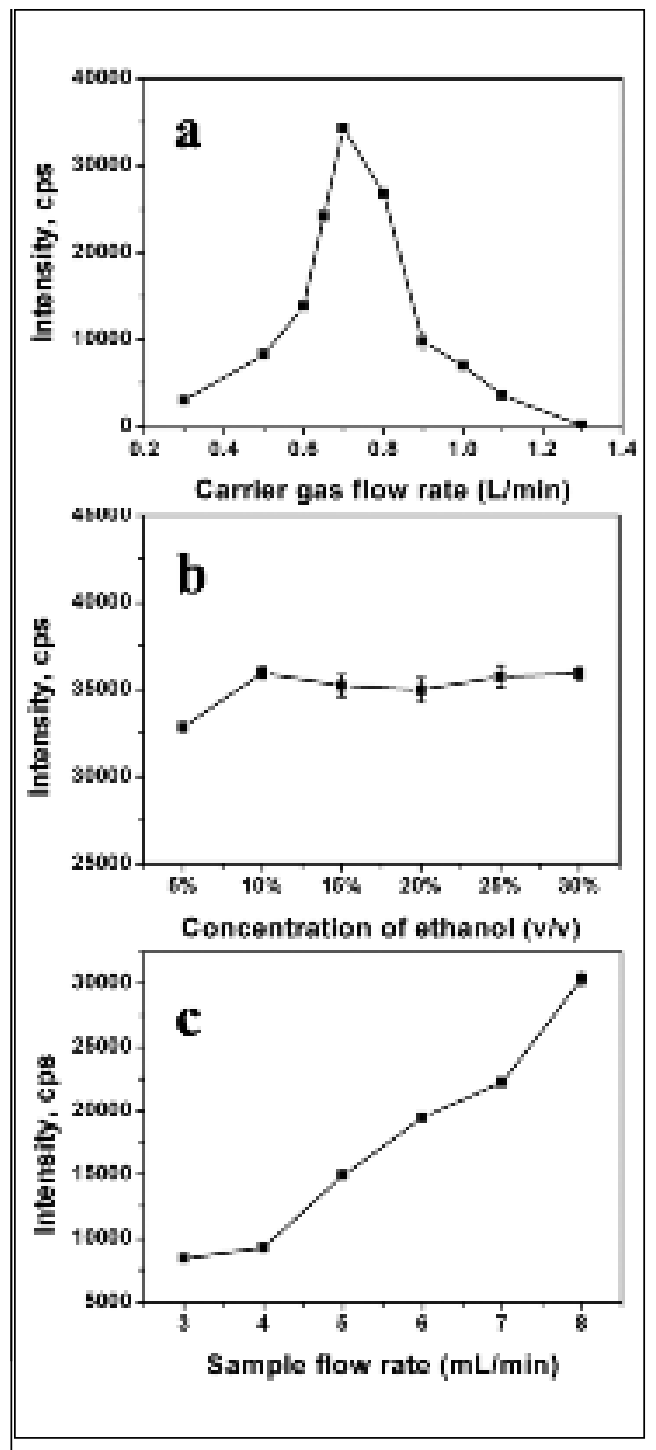

Fig. 2. Effect of argon carrier flow rate, ethanol concentration, and sample flow rate on ${ }^{202} \mathrm{Hg}$ response from $0.5 \mathrm{ng} \mathrm{mL}^{-1}$ solutions of $\mathrm{Hg}$.

(a) $10 \%(v / v)$ ethanol and $8 \mathrm{~mL} \mathrm{~min}{ }^{-1}$ sample flow rate;

(b) $0.7 \mathrm{~L} \mathrm{~min}^{-1}$ argon carrier gas, and $8 \mathrm{~mL} \mathrm{~min}^{-1}$ sample flow rate;

(c) $0.7 \mathrm{~L} \mathrm{~min}^{-1}$ argon carrier gas and $10 \%(v / v)$ ethanol.

the subsequent determination of mercury in alcoholic drinks.

\section{Analytical Figures of Merit}

The analytical characteristics were established under optimal conditions for photochemical vapor generation. The equation for 
the calibration line using peak height of the atomic mass ${ }^{202} \mathrm{Hg}$ signal intensity was as follows: $y=62063 x+439.52, R^{2}=0.9994$ where $\mathrm{y}$ is ${ }^{202} \mathrm{Hg}$ signal intensity (expressed as cps) and $\mathrm{x}$ is the $\mathrm{Hg}$ concentration (expressed as ng $\mathrm{mL}^{-1}$ ). As shown in Figure 3, the calibration curve was linear in the studied range of 0.05 to $2 \mathrm{ng} \mathrm{mL}^{-1}$ $\mathrm{Hg}$. The repeatability expressed as the relative standard deviation (RSD, n=7) was $2.3 \%$ (one day) and $3.1 \%$ (day-to-day) for mercury determination at the concentration of $0.5 \mathrm{ng} \mathrm{mL}^{-1}$. The limit of detection (LOD, $3 \sigma$ ) based on peak height

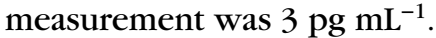

In Table II, the LOD of the proposed method is compared with some literature values involving different chemical vapor generation techniques, including matrixassisted photo CVG-AFS, photo CVG ICP-MS, and $\mathrm{NaBH}_{4}$ or $\mathrm{SnCl}_{2}$ based CVG. Also included in the table is the LOD by conventional pneumatic solution nebulization. As can be seen from Table II, the LOD of the proposed method is comparable to $\mathrm{NaBH}_{4}$ based CVGICP-MS and acetic acid-based photo CVG-ICP-MS, and better than those obtained by $\mathrm{SnCl}_{2}$ based CVG-AFS and CVG-ICP-MS, photo CVG-AFS, and pneumatic solution nebulization ICP-MS.

\section{Determination of Mercury in Alcoholic Drinks}

The analysis of alcoholic drinks such as wine and liquor is of great importance to prevent fraud and to assess toxicological issues $(26,27)$. In order to validate the accuracy of the method, a comparison of the proposed method with CVG-AFS, spike recovery experiments (alcoholic drinks spiked with mercury standard solution) and analysis of certified reference aqueous samples were carried out. As shown in Table III, the analytical results of the proposed method are in good agreement with the certified values

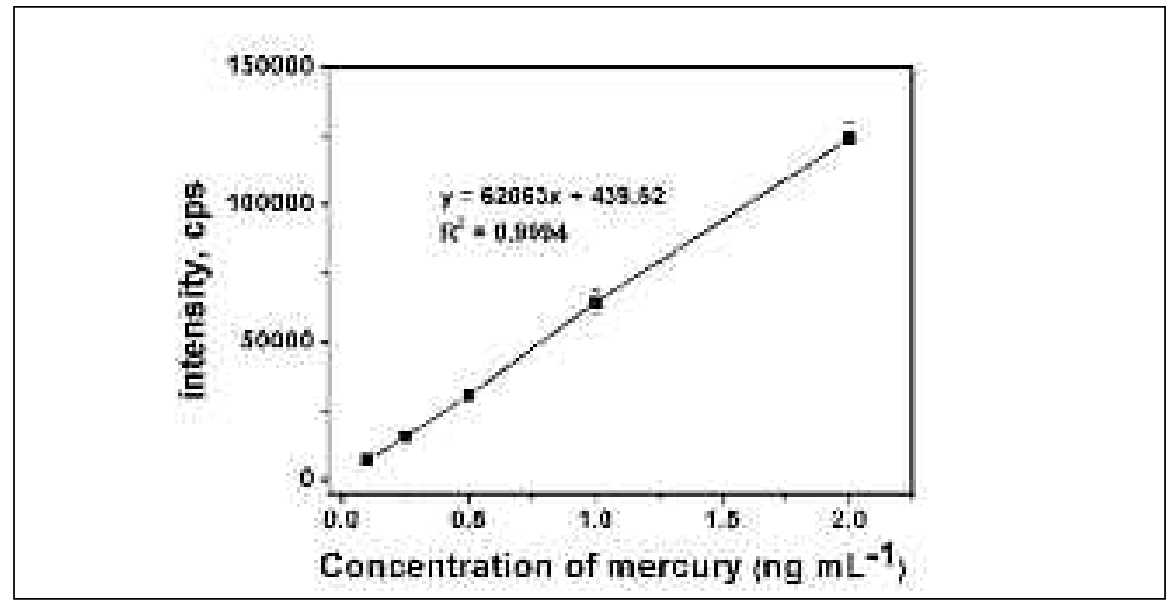

Fig. 3. Calibration curve of matrix-assisted photo CVG for mercury determination by ICP-MS.

TABLE II Comparison of LODs With Similar Methods

\begin{tabular}{lllccc}
\hline Reductant & Method & Samples & $\begin{array}{c}\text { Preconcen- } \\
\text { tration }\end{array}$ & $\begin{array}{c}\text { LOD } \\
\left(\mathrm{ng} \mathrm{mL}^{-1}\right)\end{array}$ & Ref. \\
\hline Ethanol & MA photo CVG-ICP-MS & Alcohol & - & 0.003 & This \\
& & & & & work \\
Acetic acid & MA photo CVG-AFS & Vinegar & - & 0.08 & $(28)$ \\
Ethanol & MA photo CVG-AFS & Alcohol & - & 0.07 & $(18)$ \\
Formic acid & Photo CVG-ICP-MS & Water & - & 0.003 & $(9)$ \\
$\mathrm{SnCl}_{2}$ & CVG-AES & Water & - & 0.24 & $(29)$ \\
$\mathrm{SnCl}_{2}$ & CVG-AFS & Environ- & $\mathrm{CPE}^{\mathrm{a}}$ & 0.005 & $(30)$ \\
& & mental & & & \\
- & Nebulization ICP-MS & Blood & - & 0.15 & $(26)$ \\
$\mathrm{NaBH}_{4}$ & CVG-ICPMS & Cereals & - & 0.004 & $(31)$ \\
$\mathrm{SnCl}_{2}$ & CVG-ICPMS & Blood & - & 0.08 & $(32)$ \\
\hline
\end{tabular}

${ }^{\mathrm{a}} \mathrm{CPE}=$ Cloud Point Extraction.

and the CVG-AFS method. The $t$-test was used to validate the significant difference between the certified value and the determined value of GBW(E) 080329 and GBW(E) 080939, and also between the results obtained by CVG-AFS and the proposed method. No significant difference was found at the 95\% confidence level. Furthermore, the proposed method was used for the analysis of real samples purchased at commercial markets. The recoveries of the spike recovery experiments were found to be in the $94-110 \%$ range (see Table III).

\section{CONCLUSION}

A highly sensitive, simple, and cost-effective method has been proposed for the ICP-MS determination of mercury in alcoholic drinks based on matrix-assisted photo chemical vapor generation. It is a relatively green analytical method since no additional reagent is needed in the chemical vapor generation process. Under the optimized conditions, a limit of detection $(3 \sigma)$ of $3 \mathrm{pg} \mathrm{mL}^{-1} \mathrm{Hg}$ was obtained with the dynamic linear

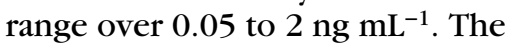
repeatability, expressed as the rela- 


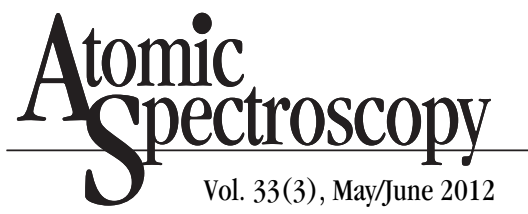

TABLE III

Analytical Results of Mercury

in Alcoholic Drinks and Certified Reference Materials

\begin{tabular}{lccccc}
\hline Sample & $\begin{array}{c}\text { Added } \\
\left(\mathrm{ng} \mathrm{mL}^{-1}\right)\end{array}$ & \multicolumn{2}{c}{ Detection $\left(\mu \mathrm{L} \mathrm{L}^{-1}\right)$} & $\begin{array}{c}\text { Recoveries } \\
\text { PFS }\end{array}$ & $\begin{array}{c}\text { Certified } \\
\left(\mu \mathrm{gL}^{-1}\right)\end{array}$ \\
\hline GBW(E)080329 & - & - & $9.7 \pm 0.2$ & 97 & $10 \pm 0.5$ \\
GBW(E)080939 & - & - & $98 \pm 3$ & 98 & $100 \pm 4$ \\
Wine 1 & - & nd & $\begin{array}{c}\text { nd } \\
\text { ICP-MS }\end{array}$ & - & - \\
Wine 2 & 0.5 & & $0.52 \pm 0.02$ & 104 & - \\
& - & nd & nd & - & - \\
Wine 3 & 0.5 & & $0.47 \pm 0.01$ & 94 & - \\
& - & nd & nd & - & - \\
Liquor 1 & 0.5 & & $0.54 \pm 0.03$ & 108 & - \\
& - & $0.43 \pm 0.01$ & $0.41 \pm 0.02$ & - & - \\
Liquor 2 & 0.5 & $0.90 \pm 0.02$ & $0.88 \pm 0.03$ & 94 & - \\
& - & $0.32 \pm 0.03$ & $0.35 \pm 0.02$ & - & - \\
& 0.5 & $0.84 \pm 0.02$ & $0.90 \pm 0.04$ & 110 & - \\
\hline
\end{tabular}

tive standard deviation $(\mathrm{n}=7)$, was $2.3 \%$ (one day) and $3.1 \%$ (day-today) for mercury determination at the concentration of $0.5 \mathrm{ng} \mathrm{mL}-1$.

Besides an alcohol matrix, some other low molecular weight organic compound matrices, such as vinegar, may also be feasible for matrixassisted photo CVG-ICP-MS. Due to the high sensitivity as well as simplicity and cost-effectiveness, the proposed method has the potential to be used for the determination of other photochemical vapor generation elements in low molecular weight organic compound-containing matrices.

\section{ACKNOWLEDGMENT}

The authors gratefully acknowledge the financial support for this project from the scientific research foundation provided by Chengdu University of Technology and the Science and Technology Project of Sichuan Province (No. 07J Y0292028). Received April 9, 2012.

\section{REFERENCES}

1. H. Matusiewicz and R.E. Sturgeon, Appl. Spectrosc. Rev. 47, 41 (2012).

2. B. Yuksel, G. Mergen, and T. Soylemezoglu, At. Spectrosc. 31, 1 (2010).

3. R. Liu, P. Wu, K. Xu, Y. Lv, and X. Hou, Spectrochim. Acta, Part B, At. Spectrosc. 63, 704 (2008).

4. C.J. Zeng, N. Zhou, and J.W. Luo, J. Anal. At. Spectrom. 27, 120 (2012).

5. P. Wu, L.A. He, C.B. Zheng, X.D. Hou, and R.E. Sturgeon, J. Anal. At. Spectrom. 25, 1217 (2010).

6. Y. Gao, Z. Shi, Z. Long, P. Wu, C. Zheng, and X. Hou, Microchem. J. 103, 1 (2012).

7. Y.G. Yin, J.F. Liu, and G.B. Jiang, (2011).

8. C.F. Han, C.B. Zheng, J. Wang, G.L. Cheng, Y. Lv, and X.D. Hou, Anal. Bioanal. Chem. 388, 825 (2007).

9. L. Wu, C.B. Zheng, Q. Ma, C.W. Hu, X. Hou, Appl. Spectrosc. Rev. 42, 79 (2007).

10. Y. Gao, W.L. Yang, C.B. Zheng, X.D. Hou, and L. Wu, J. Anal. At. Spectrom. 26, 126 (2011).

11. J.A. Nobrega, R.E. Sturgeon, P. Grinberg, G.J. Gardner, C.S. Brophy, and E.E. Garcia, J. Anal. At. Spectrom. 26, 2519 (2011).

12. C.B. Zheng, Y. Li, Y.H. He, Q. Ma, and X.D. Hou, J. Anal. At. Spectrom. 20, 746 (2005). Trac-Trends Anal. Chem. 30, 1672
13. J. Liang, Q.Q. Wang, and B.L. Huang, Anal. Bioanal. Chem. 381, 366 (2005).

14. C.B. Zheng, Q. Ma, L. Wu, X.D. Hou, and R.E. Sturgeon, Microchem. J. 95, 32 (2010).

15. C.B. Zheng, L. Yang, R.E. Sturgeon, and X.D. Hou, Anal. Chem. 82, 3899 (2010).

16. P. Grinberg, Z. Mester, R.E. Sturgeon, A. Ferretti, J. Anal. At. Spectrom. 23, 583 (2008).

17. P. Grinberg, R.E. Sturgeon, Spectrochim. Acta Part B 64, 235 (2009).

18. Y. Li, C.B. Zheng, Q. Ma, L. Wu, C.W. Hu, and X.D. Hou, J. Anal. At. Spectrom. 21, 82 (2006).

19. D. Beauchemin, Mass Spectrom. Rev. 29, 560 (2010).

20. C. Engelhard, Anal. Bioanal. Chem. 399, 213 (2011).

21. K. Dash, G. Venkateswarlu, S. Thangavel, S.V. Rao, and S.C. Chaurasia, Microchem. J. 98, 312 (2011).

22. R. Liu, X. Liu, Y.R. Tang, L. Wu, X.D. Hou, and Y. Lv, Anal. Chem. 83, 2330 (2011).

23. R. Liu, Y. Lv, X.D. Hou, Z. Mester, and L. Yang, Anal. Chem. 84, 2769 (2012).

24. X.M. Guo, R.E. Sturgeon, Z. Mester, and G.J. Gardner, Anal. Chem. 76, 2401 (2004).

25. J.T. Madden, and N. Fitzgerald, Spectrochim. Acta, Part B, At. Spectrosc. 64, 925 (2009).

26. G. Grindlay, J. Mora, L. Gras, and M.T.C. de Loos-Vollebregt, Anal. Chim. Acta 691, 18 (2011).

27. I. Aydin, U. Yuksel, R. Guzel, B. Ziyadanogullari, and F. Aydin, Atom. Spectrosc. 31, 67 (2010).

28. Y. Liang, X.Y. Liu, D.X. Yuan, Z.B. Gong, and $Z$. Zhang, Water Environ. Res. 82, 335 (2010).

29. A.S. Ribeiro, M.A. Vieira, P. Grinberg, and R.E. Sturgeon, J. Anal. At. Spectrom. 24, 689 (2009).

30. C.G. Yuan, K. Lin, and A. Chang, Microchim. Acta 171, 313 (2010).

31. F.Y. Chen, and S. J. Jiang, J. Agr. Food Chem. 57, 6564 (2009).

32. J.L. Rodrigues, D.P. Torres, V.C. de Oliveira Souza, B.L. Batista, S.S. de Souza, A.J. Curtius, and F. Barbosa, Jr., J. Anal. At. Spectrom. 24, 1414 (2009). 